\title{
Multi-Quality Characteristics Optimization of WEDM for IN-625 by Applying Taguchi DEAR Technique
}

\author{
S. Sonawane ${ }^{1}$ and M. Kulkarni ${ }^{2}$ \\ ${ }^{1}$ Research Scholar, Walchand Institute of Technology, Solapur, India \\ ${ }^{2}$ Professor, Rajarshi Shahu School of Engineering and Research, Narhe, Pune, India \\ \{sonawanesachin09@gmail.com\}
}

\begin{abstract}
To manufacture quality products at lowest cost in industries, optimization is an effective technique which can be applied to find out the best manufacturing conditions. The objective of this research work is to examine the effect of control factors and to choose the correct settings of these factors to maximize MRR and minimize surface roughness and overcut while WEDM of Inconel-625. The control factors chosen for the study are pulse on time, pulse off time, servo voltage, peak current, wire feed rate and wire tension. Experiments were planned as per Taguchi's L27 orthogonal design under diverse cutting conditions of control factors. Data envelopment analysis based ranking technique (DEAR) was employed for multi-quality characteristic optimization. The optimal values of control factors was found as pulse on time $118 \mu \mathrm{s}$, pulse of time $41 \mu \mathrm{s}$, servo voltage 30 volts, peak current $230 \mathrm{Amp}$, wire feed rate $1 \mathrm{~m} / \mathrm{min}$ and wire tension $5 \mathrm{Gram}$. From the outcomes of the ANOVA, Pulse-on time was found to be the major significant factor affecting the quality characteristics.
\end{abstract}

Keywords: WEDM, Taguchi method, Inconel-625, DEAR, multi-quality characteristic optimization, ANOVA

\section{Introduction}

Nickel based alloys finds wide applications in different parts of gas turbines of aircraft, steam turbine power plants, reciprocating engines, tool \& die industry, medical field, heat treatment equipments, nuclear power plants, chemical industries, pollution control apparatus and in coal gasification and liquefaction systems. As nickel based super alloys possesses high hardness, high strength at elevated temperature, low thermal diffusivity and high chemical reactivity with the tool materials, they are very difficult to machine conventionally. This leads to nick wear of the tool nose, abrasive wear of the tool, greater diffusion wear rate, fragmentation of the tool rake face, degradation of tool material by seizure and cratering, increase in the temperature of tool tip and uneven temperature distribution in the cutting tool. [1,2]. Wire electrical discharge machining (WEDM) is one of the significant non-conventional thermoelectric process for machining of materials with high hardness, chemically reactive and which are difficult to machine using conventional methods. In WEDM material removal takes place due to melting and evaporation by thermal energy produced due to continuous discrete sparks. It finds major applications in aerospace, nuclear and automotive industries to cut intricate shapes in electrically conductive materials. Liao and Chen [3] used DEAR method for multi-objective optimization and found that the proposed method eliminates uncertainty and complication associated with PCA and Taguchi method. Sahu et.al. [4] carried out experiments on AISI D2 steel with response surface methodology to find out the effect of machining parameters on MRR, TWR, surface roughness and circularity. Data envelopment analysis was applied to find out optimal responses. Chalisgaonkar and Kumar [5] applied utility concept approach to determine optimal combination of parameters while WEDM of pure titanium. Rajyalashmi and Ramaiah [6] used grey relational analysis to carry out multi-response optimization of WEDM parameters while machining Inconel-825. Reddy et. al. [7] applied Taguchi based DEAR method to optimize the process parameters of EDM.

B. Iyer, S. Nalbalwar and R. Pawade (Eds.)

ICCASP/ICMMD-2016. Advances in Intelligent Systems Research.

Vol.137, Pp. 1-6.

(C) 2017. The authors - Published by Atlantis Press

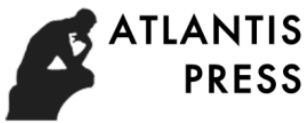

This is an open access article under the CC BY-NC license (http://creativecommons.org/licens)es/by-nc/4.0/). 
This paper reports multi-quality characteristic optimization of control factors while wire electrical discharge machining of Inconel-625 using Taguchi method integrated with data envelopment analysis based ranking method (DEAR).

Taguchi's L27 orthogonal array was applied for experimental design. ANOVA was performed to find out the major significant factor which affects the quality characteristics.

\section{Experimental Work}

Inconel-625 was selected as a work piece material for the present experimental investigation with dimensions 30 $\mathrm{mm} \times 30 \mathrm{~mm}$ x $5 \mathrm{~mm}$ thickness. With the help of Brass wire of diameter $0.25 \mathrm{~mm}$ as a tool electrode, a block of $10 \mathrm{~mm} \times 10 \mathrm{~mm}$ × $5 \mathrm{~mm}$ was cut from the work piece. Taguchi's L27 orthogonal design was used for experimental planning. Six control factors considered for study were pulse on time, pulse off time, servo voltage, peak current, wire feed rate and wire tension. Control factors along with their levels are shown in Table 1. The quality characteristics selected for this study were MRR, surface roughness and overcut. The "lower-thebetter" quality characteristic has been used for calculating signal to noise ratio $(\mathrm{S} / \mathrm{N})$ of surface roughness and overcut, whereas "higher-the better" quality characteristic for MRR.

Eq. 1 and 2 .

$\zeta \mathrm{LB}=-10 \log \left[\frac{1}{n} \sum_{1}^{n} Z i j^{2}\right]$

$\zeta \mathrm{HB}=-10 \log \left[\frac{1}{n} \sum_{1}^{n} 1 / Z i j^{2}\right]$

where $\mathrm{Zij}$ is the response of the ith experiment at the $\mathrm{jth}$ test and $\mathrm{n}$ is the total number of repetitions.

Mitutoyo make surface roughness tester SJ-201 was used to measure surface finish in $\mu \mathrm{m}$ on the machined square block. MRR and overcut were calculated by using following equations:

$$
\begin{aligned}
& \text { MRR }=\frac{\text { Volumeofmaterialremoved }}{\text { Timetakeninmin }} \\
& \text { Overcut }=\frac{\text { Widthofcut }-D}{2}
\end{aligned}
$$

Where, $\mathrm{D}=$ wire diameter in $\mathrm{mm}$

Width of cut is the algebraic difference of dimensions of square on the work piece and square block. MRR was measured in $\mathrm{mm} 3 / \mathrm{min}$ and overcut in $\mathrm{mm}$. Statistical analysis was carried out using Minitab 16 software. Table 2 shows Taguchi's L27 orthogonal design along with the results obtained from the experiments and corresponding $\mathrm{S} / \mathrm{N}$ ratios.

\section{Data Envelopment Analysis based Ranking (DEAR) technique}

In DEAR technique, a set of unique quality characteristics are converted into a ratio which is called as multiquality characteristic index (MQCI). This MQCI value is used to determine optimal settings of control factors. The different steps in DEAR technique are as follows:

I. Compute the weight of each quality characteristic: The weight of each quality characteristic is the ratio of value of quality characteristic at any particular experiment to the summation of values of quality characteristic of all experiments. Weights are computed by applying the following equations:

$\beta S R=\frac{\left(\frac{1}{S R}\right)}{\left(\sum 1 / S R\right)}$ 


$$
\begin{aligned}
& \beta \mathrm{OC}=\frac{\left(\frac{1}{O C}\right)}{\left(\sum 1 / O C\right)} \\
& \beta \mathrm{MRR}=\frac{M R R}{\left(\sum M R R\right)}
\end{aligned}
$$

Table 1 Control factors and their levels

\begin{tabular}{|c|c|c|c|c|c|}
\hline Symbol & Control Factor & Unit & Level 1 & Level 2 & Level 3 \\
\hline A & Pulse on Time & $\mu \mathrm{s}$ & 110 & 114 & 118 \\
\hline B & Pulse off Time & $\mu \mathrm{s}$ & 41 & 46 & 51 \\
\hline C & Servo Voltage & Volts & 20 & 30 & 40 \\
\hline D & Peak Current & Amp & 170 & 200 & 230 \\
\hline E & Wire Feed Rate & $\mathrm{m} / \mathrm{min}$ & 1 & 3 & 5 \\
\hline F & Wire Tension & Gram & 2 & 5 & 8 \\
\hline
\end{tabular}

\begin{tabular}{|c|c|c|c|c|c|c|c|c|c|c|c|c|}
\hline $\begin{array}{l}\text { Ex. } \\
\text { No. }\end{array}$ & $\mathbf{A}$ & B & $\mathrm{C}$ & D & $\mathbf{E}$ & $\mathbf{F}$ & $\begin{array}{c}\text { SR } \\
(\mu \mathrm{m})\end{array}$ & $\begin{array}{c}\mathrm{S} / \mathrm{N} \\
\text { ratio }\end{array}$ & $\begin{array}{c}\mathbf{O C} \\
(\mathrm{mm})\end{array}$ & $\begin{array}{c}\mathrm{S} / \mathbf{N} \\
\text { ratio }\end{array}$ & $\begin{array}{c}\text { MRR } \\
\left(\mathrm{mm}^{3} / \mathrm{min}\right)\end{array}$ & $\begin{array}{c}\mathrm{S} / \mathrm{N} \\
\text { ratio }\end{array}$ \\
\hline 1. & 110 & 41 & 20 & 170 & 1 & 2 & 1.82 & -5.2332 & 0.370 & 8.6212 & 33.30 & 29.9882 \\
\hline 2. & 110 & 41 & 20 & 170 & 3 & 5 & 1.68 & -4.3511 & 0.230 & 12.749 & 27.60 & 28.2153 \\
\hline 3. & 110 & 41 & 20 & 170 & 5 & 8 & 1.60 & -3.9551 & 0.265 & 11.523 & 26.60 & 27.712 \\
\hline 4. & 110 & 46 & 30 & 200 & 1 & 2 & 1.76 & -4.7944 & 0.402 & 7.9133 & 31.16 & 29.3075 \\
\hline 5. & 110 & 46 & 30 & 200 & 3 & 5 & 1.70 & -4.4375 & 0.224 & 13.007 & 28.43 & 28.6294 \\
\hline 6. & 110 & 46 & 30 & 200 & 5 & 8 & 1.61 & -4.0827 & 0.300 & 10.419 & 26.64 & 27.7466 \\
\hline 7. & 110 & 51 & 40 & 230 & 1 & 2 & 1.79 & -5.0095 & 0.340 & 9.3529 & 32.25 & 29.6556 \\
\hline 8. & 110 & 51 & 40 & 230 & 3 & 5 & 1.58 & -3.8283 & 0.380 & 8.4023 & 25.67 & 27.6978 \\
\hline 9. & 110 & 51 & 40 & 230 & 5 & 8 & 1.52 & -3.5025 & 0.168 & 15.492 & 24.53 & 27.6619 \\
\hline 10. & 114 & 41 & 30 & 230 & 1 & 5 & 2.32 & -7.3475 & 0.320 & 9.8773 & 55.00 & 34.5062 \\
\hline 11. & 114 & 41 & 30 & 230 & 3 & 8 & 2.19 & -6.9537 & 0.270 & 11.345 & 48.63 & 33.8563 \\
\hline 12. & 114 & 41 & 30 & 230 & 5 & 2 & 1.85 & -5.3749 & 0.167 & 15.528 & 33.70 & 30.2365 \\
\hline 13. & 114 & 46 & 40 & 170 & 1 & 5 & 2.28 & -7.1217 & 0.186 & 14.625 & 52.37 & 34.1899 \\
\hline 14. & 114 & 46 & 40 & 170 & 3 & 8 & 1.79 & -5.1215 & 0.179 & 14.958 & 32.92 & 29.7878 \\
\hline 15. & 114 & 46 & 40 & 170 & 5 & 2 & 2.01 & -6.0496 & 0.176 & 15.106 & 37.62 & 30.7563 \\
\hline 16. & 114 & 51 & 20 & 200 & 1 & 5 & 1.95 & -5.6816 & 0.286 & 10.872 & 34.00 & 30.4922 \\
\hline 17. & 114 & 51 & 20 & 200 & 3 & 8 & 2.06 & -6.3054 & 0.165 & 15.65 & 39.20 & 31.0776 \\
\hline 18. & 114 & 51 & 20 & 200 & 5 & 2 & 1.97 & -5.772 & 0.159 & 15.972 & 36.60 & 30.5405 \\
\hline 19. & 118 & 41 & 40 & 200 & 1 & 8 & 2.51 & -7.9132 & 0.352 & 9.0606 & 58.70 & 34.9792 \\
\hline 20. & 118 & 41 & 40 & 200 & 3 & 2 & 2.04 & -6.2784 & 0.172 & 15.303 & 38.90 & 30.9849 \\
\hline 21. & 118 & 41 & 40 & 200 & 5 & 5 & 2.41 & -7.5559 & 0.164 & 15.721 & 56.34 & 34.6794 \\
\hline 22. & 118 & 46 & 20 & 230 & 1 & 8 & 2.10 & -6.568 & 0.404 & 7.8794 & 44.37 & 31.6185 \\
\hline 23. & 118 & 46 & 20 & 230 & 3 & 2 & 2.36 & -7.4225 & 0.288 & 10.822 & 55.20 & 34.6204 \\
\hline 24. & 118 & 46 & 20 & 230 & 5 & 5 & 2.25 & -6.9922 & 0.200 & 14.108 & 50.90 & 33.9312 \\
\hline 25. & 118 & 51 & 30 & 170 & 1 & 8 & 2.50 & -7.7954 & 0.212 & 13.473 & 57.60 & 34.9689 \\
\hline 26. & 118 & 51 & 30 & 170 & 3 & 2 & 2.31 & -7.3226 & 0.163 & 15.755 & 54.50 & 34.4202 \\
\hline 27. & 118 & 51 & 30 & 170 & 5 & 5 & 1.73 & -4.592 & 0.180 & 14.892 & 29.20 & 29.0937 \\
\hline
\end{tabular}

Table 2 Taguchi's $L_{27}$ orthogonal design with quality characteristics and respective $S / N$ ratios

II. Transform each quality characteristic value into weighted values by multiplying each characteristic value with its own weight using the following equations:

$\mathrm{s}=\mathrm{SR} X \beta \mathrm{SR}$

$\mathrm{oc}=\mathrm{OC} \times \beta \mathrm{OC}$

$m=$ MRR X $\beta M R R$ 
III. Divide the larger-the-better characteristic with smaller the better characteristic to get the MQCI value using the following equation

$\mathrm{MQCI}=\frac{m}{(s+o c)}(1$

\section{Results and Discussion}

Fig. 1 to 3 depicts the effect of control factors on quality characteristics. From Fig. $1 \& 2$ it is found that as there is an increase in the value of pulse-on time and peak current, stronger sparks with greater amount of discharge energy is produced. These sparks strikes the work piece, resulting in melting of material and produces large and deep craters on the work piece surface. This results in significant increase in the values surface finish and MRR. With increase in pulse-off time, discharge energy produced per spark decreases resulting in decrease of MRR and surface finish. As servo voltage increases, there is delay in the discharge which results in the generation of less discharge energy. This leads to decrease in the value of surface roughness and MRR. At low values of wire feed rate, duration of contact between wire and work piece increases values of surface roughness and MRR increases. Wire tension has no significant effect on surface roughness and MRR.Fig. 3 shows that as pulse on time increases, overcut first decreases rapidly then increases very slightly. With increase in the value pulse off time, overcut first increases and then decreases. Values of overcut decreases, with the increment in peak current and servo voltage. Increase in wire tension value leads to higher overcut. Effect of wire feed rate is not very significant.
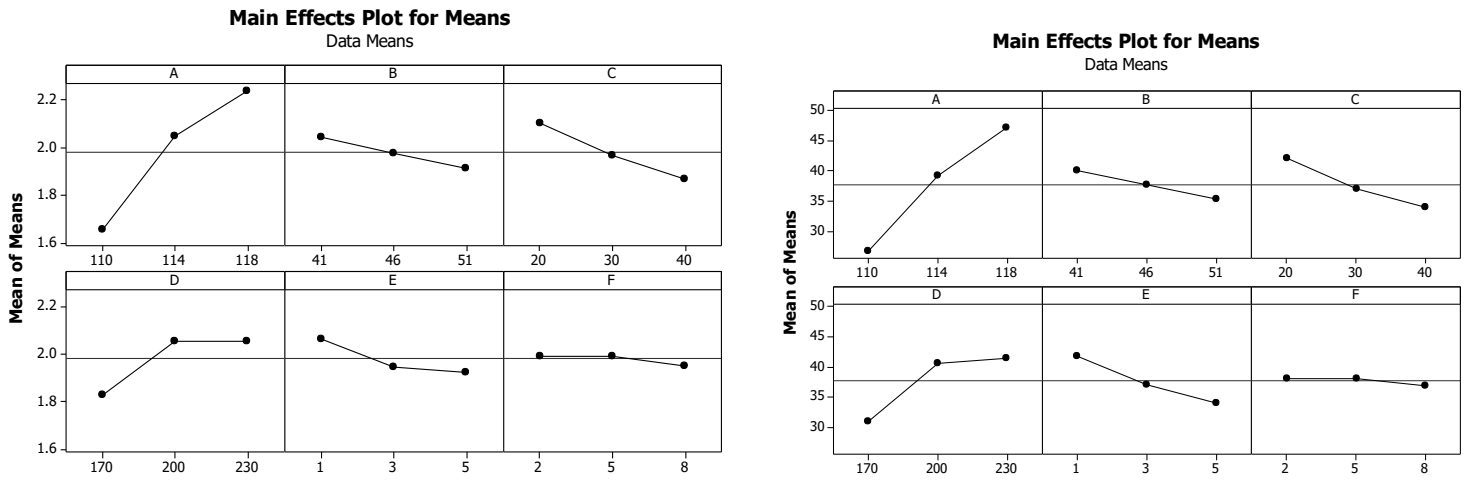

Fig. 1. Effect of control factors on surface roughness

Fig. 2. Effect of control factors on MRR

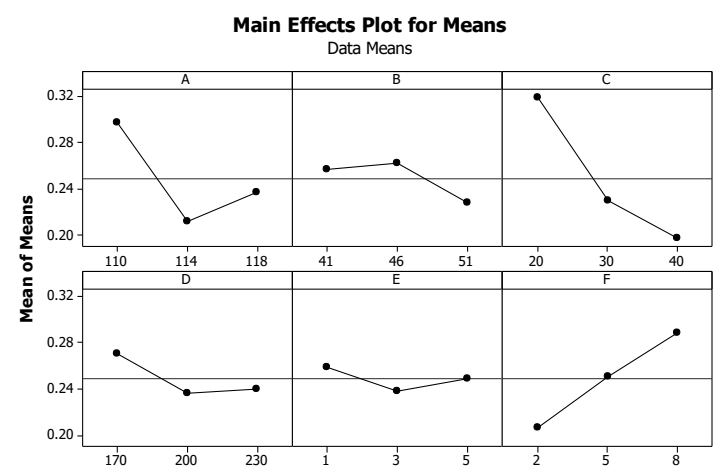

Fig. 3. Effect of control factors on overcut

Further, multi-quality characteristic optimization was carried out by applying Taguchi-DEAR technique. Weights of the quality characteristics and MQCI values are computed by using Eqs. (5) to (11). These values are represented in Table 3. Highest value of MQCI for a particular control factor represents optimal level for that factor. From Table 4 values of optimal control factors were found to be pulse on time $118 \mu \mathrm{s}$, pulse of time $41 \mu \mathrm{s}$, servo voltage 30 volts, peak current $230 \mathrm{Amp}$, wire feed rate $1 \mathrm{~m} / \mathrm{min}$ and wire tension $5 \mathrm{Gram}$. From the outcomes of ANOVA, it is found that pulse on time is the most noteworthy factor affecting the quality 
characteristics. Confirmation experiments were conducted at the optimal settings of control factors. Table 5 depicts the outcomes of confirmation experiments.

Table 3 Weights and MQCI values for all experiments

\begin{tabular}{|c|c|c|c|c|}
\hline \multirow[t]{2}{*}{ Exp. No. } & \multicolumn{3}{|c|}{ Weights } & \multirow[t]{2}{*}{ MQCI } \\
\hline & $\begin{array}{c}\text { Surface roughness } \\
\beta_{\mathrm{SR}}\end{array}$ & $\begin{array}{c}\text { Overcut } \\
\beta_{O C}\end{array}$ & $\begin{array}{l}\text { MRR } \\
\beta_{\text {MRR }}\end{array}$ & \\
\hline 1. & 0.039573 & 0.022513 & 0.031065 & 12.87419 \\
\hline 2. & 0.042871 & 0.036217 & 0.025748 & 8.844019 \\
\hline 3. & 0.045015 & 0.031434 & 0.024815 & 8.214758 \\
\hline 4. & 0.040922 & 0.020721 & 0.029069 & 11.27266 \\
\hline 5. & 0.042367 & 0.037187 & 0.026522 & 9.383939 \\
\hline 6. & 0.044735 & 0.027766 & 0.024852 & 8.239482 \\
\hline 7. & 0.040237 & 0.024500 & 0.030086 & 12.07511 \\
\hline 8. & 0.045584 & 0.021921 & 0.023947 & 7.650384 \\
\hline 9. & 0.047384 & 0.049583 & 0.022884 & 6.985968 \\
\hline 10. & 0.031045 & 0.026031 & 0.051309 & 35.12019 \\
\hline 11. & 0.032887 & 0.030851 & 0.045367 & 27.45617 \\
\hline 12. & 0.038932 & 0.04988 & 0.031439 & 13.18534 \\
\hline 13. & 0.031589 & 0.044784 & 0.048856 & 31.84173 \\
\hline 14. & 0.040237 & 0.046536 & 0.030711 & 12.58204 \\
\hline 15. & 0.035833 & 0.047329 & 0.035096 & 16.43119 \\
\hline 16. & 0.036935 & 0.029125 & 0.031718 & 13.42114 \\
\hline 17. & 0.034963 & 0.050484 & 0.03657 & 17.84036 \\
\hline 18. & 0.03656 & 0.052389 & 0.034144 & 15.55227 \\
\hline 19. & 0.028695 & 0.023664 & 0.054761 & 40.00439 \\
\hline 20. & 0.035306 & 0.04843 & 0.03629 & 17.56834 \\
\hline 21. & 0.029885 & 0.050792 & 0.052559 & 36.85235 \\
\hline 22. & 0.034297 & 0.020619 & 0.041393 & 22.85653 \\
\hline 23. & 0.030518 & 0.028923 & 0.051496 & 35.37607 \\
\hline 24. & 0.03201 & 0.041649 & 0.047484 & 30.07925 \\
\hline 25. & 0.028809 & 0.039292 & 0.053735 & 38.51913 \\
\hline 26. & 0.031179 & 0.051104 & 0.050843 & 34.48454 \\
\hline 27. & 0.041632 & 0.046277 & 0.027241 & 9.899134 \\
\hline
\end{tabular}

Table 4 Response table for MQCI

\begin{tabular}{ccccccc}
\hline Level & A & B & C & D & E & F \\
\hline 1 & 9.505 & $\mathbf{2 2 . 2 3 6}$ & 18.340 & 19.299 & $\mathbf{2 4 . 2 2 1}$ & 18.758 \\
2 & 20.381 & 19.785 & $\mathbf{2 0 . 8 4 0}$ & 18.904 & 19.021 & $\mathbf{2 0 . 3 4 4}$ \\
3 & $\mathbf{2 9 . 5 1 6}$ & 17.381 & 20.221 & $\mathbf{2 1 . 1 9 8}$ & 16.160 & 20.300 \\
Delta & 20.011 & 4.855 & 2.5 & 2.294 & 8.061 & 1.586 \\
\hline
\end{tabular}

Table 5 Outcomes of the confirmation experiments at the optimal settings of control factors

\begin{tabular}{|c|c|c|c|}
\hline \multirow{2}{*}{ Sr. No. } & Quality characteristic & \multicolumn{2}{|c|}{ Optimum value } \\
\cline { 3 - 4 } & & Predicted value & Experimental value \\
\hline 1. & Surface roughness, $\mu \mathrm{m}$ & - & 2.38 \\
\hline 2. & Overcut, $\mathrm{mm}$ & - & 0.341 \\
\hline 3. & $\mathrm{MRR}, \mathrm{mm}^{3} / \mathrm{min}$ & - & 59.36 \\
\hline 4. & $\mathrm{MQCI}$ & 40.00439 & 41.3517 \\
\hline
\end{tabular}

\begin{tabular}{|c|c|c|c|c|c|}
\hline \multicolumn{7}{|c|}{ Table 6 ANOVA for MQCI } & F & P \\
\hline Factors & DF & Seq SS & Adj MS & 12.2 & $0.001^{*}$ \\
\hline A & 2 & 1806.54 & 903.269 & 0.72 & 0.506 \\
\hline B & 2 & 106.06 & 53.029 & 0.21 & 0.816 \\
\hline C & 2 & 30.52 & 15.261 & 0.18 & 0.835 \\
\hline D & 2 & 27.08 & 13.542 & 2.03 & 0.168 \\
\hline E & 2 & 300.59 & 150.294 & 0.1 & 0.906 \\
\hline F & 2 & 14.68 & 7.342 & & \\
\hline Residual Error & 14 & 1036.86 & 74.061 & & \\
\hline
\end{tabular}

\footnotetext{
* Significant at $95 \%$ confidence level
} 


\section{Conclusions}

In this research work, Taguchi based DEAR technique is applied for multi-quality characteristic optimization while WEDM of Inconel-625. The optimal settings of control factors obtained are pulse on time $118 \mu$ s, pulse of time $41 \mu \mathrm{s}$, servo voltage 30 volts, peak current $230 \mathrm{Amp}$, wire feed rate $1 \mathrm{~m} / \mathrm{min}$ and wire tension $5 \mathrm{Gram}$. Outcomes of the ANOVA represent that pulse-on time is the major considerable factor affecting the quality characteristics.

\section{References}

[1]. I.A. Choudhary, M.A. El-Baradie MA, "Machinability of nickel-base super alloys: a general review" Journal of Materials Processing Technology, 77(1998) 278-284.

[2]. E.O.Ezugwu, Z.M. Wang, A.R. Machado, "The machinability of nickel-based alloys: a review", Journal of Materials Processing Technology, 86 (1999) 1-16.

[3]. H.C. Liao, Y.K. Chen, "Optimizing multi-response problem in the Taguchi method by DEA based ranking method", International Journal of Quality \& Reliability Management, 19 (2002) 825-837.

[4]. J. Sahu, C.P. Mohanty, S.S. Mahapatra, "A DEA approach for optimization of multiple responses in Electrical Discharge Machining of AISI D2 steel”, Procedia Engineering, 51 (2013) 585-591.

[5]. R. Chalisgaonkar, J. Kumar, " Optimization of WEDM process parameters of pure titanium with multiple performance characteristics using Taguchi's DOE approach and utility concept", Frontiers of Mechanical Engineering, 8 (2013) 201-214.

[6]. G. Rajyalakshmi and P. V. Ramaiah, "Multiple process parameter optimization of wire electrical discharge machining on Inconel 825 using Taguchi grey relational analysis", International Journal of Advanced Manufacturing Technology, 69 (2013) 1249-1262.

[7]. V.V. Reddy, P.M. Valli, A. Kumar, C.S. Reddy, “ Multi-objective optimization of electrical discharge machining of PH17-4 stainless steel with surfactant-mixed and graphite powder-mixed dielectric using Taguchi-data envelopment analysis-based ranking method", Proceedings of the Institution of Mechanical Engineers Part B: Journal of Engineering Manufacture, (2014) DOI: $10.1177 / 0954405414530904$. 